\title{
Temperature and tropopause characteristics from reanalyses data in the tropical tropopause layer
}

Susann Tegtmeier et al.

Correspondence to: Susann Tegtmeier (susann.tegtmeier@usask.ca)

The copyright of individual parts of the supplement might differ from the CC BY 4.0 License. 


\section{Supplement for}

Temperature and tropopause characteristics from reanalyses data in the tropical tropopause layer

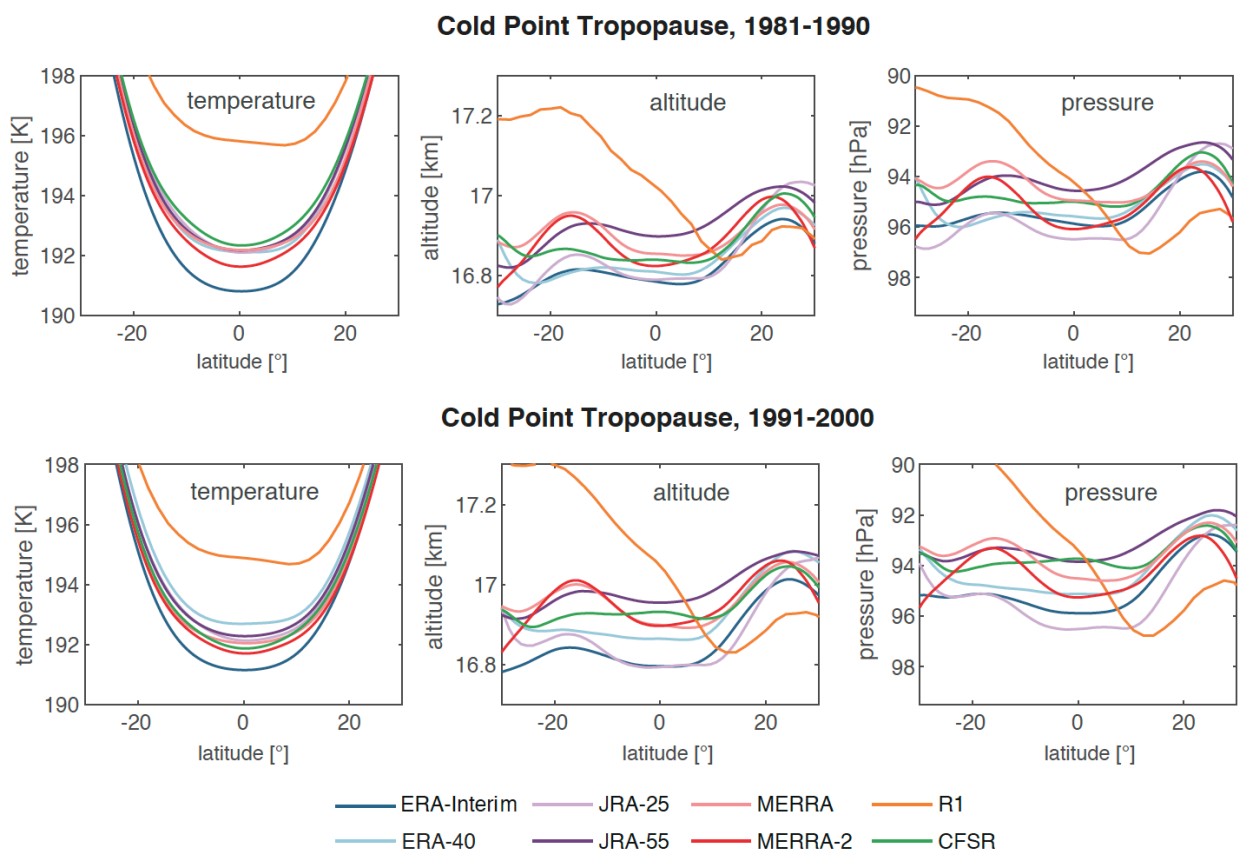

Figure S1. Latitudinal distributions of zonal-mean lapse rate tropopause temperature (left), altitude (centre) and pressure (right) for reanalysis products during 1981-1990 (upper row) and 1991-2000 (lower row).
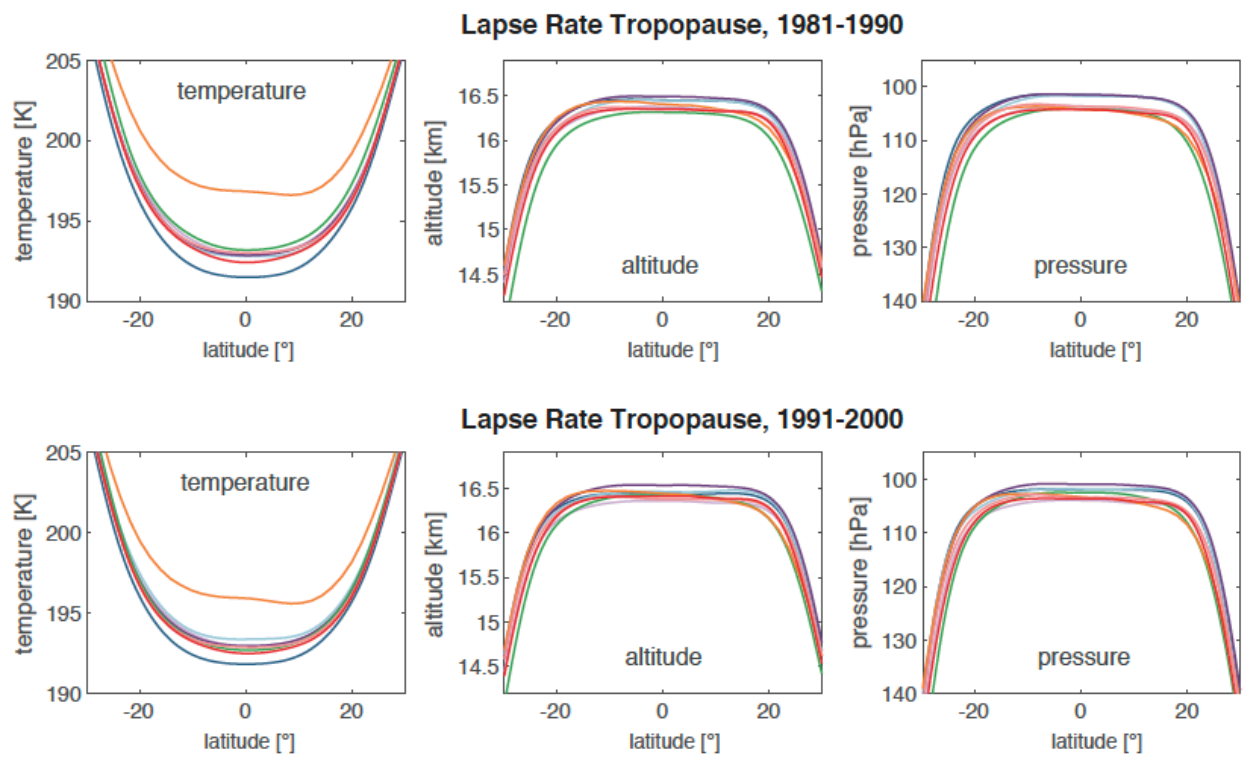

Lapse Rate Tropopause, 1991-2000
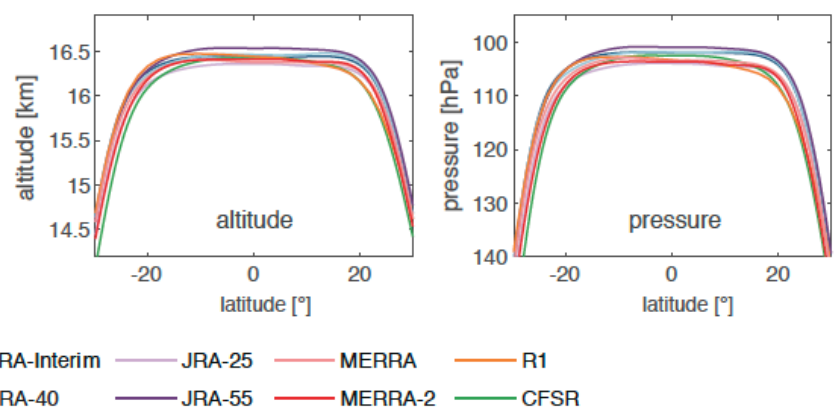

Figure S2. Latitudinal distributions of zonal-mean lapse rate tropopause temperature (left), altitude (centre) and pressure (right) for reanalysis products during 1981-1990 (upper row) and 1991-2000 (lower row). 